\title{
Inventory Decision Model of Single-echelon and Two-indenture Repairable Spares
}

\author{
Liu Chenyu \\ Naval Aeronautical and Astronautical University Qingdao Branch \\ Qingdao 266041, China \\ Zhou Bin \\ Naval Aeronautical and Astronautical University Qingdao Branch \\ Qingdao 266041, China
}

\author{
Guo Feng \\ Naval Aeronautical and Astronautical University Qingdao Branch \\ Qingdao 266041, China \\ e-mail:gf536149@163.com \\ Zhang Suqin \\ Naval Aeronautical and Astronautical University Qingdao Branch \\ Qingdao 266041, China
}

\begin{abstract}
According to the three conditions that the varianceto-mean ratio of the spares demand is larger than, equal to or less than 1, put forward the three demand distributions such as the Negative binomial distribution, Poisson distribution and Binomial distribution. For the problem that the two-level materials demand follows the Poisson distribution, use the Negative binomial distribution to improve the forecast accuracy. In the given total security funds as constraint conditions, through total shortfall minimum instead of supply availability maximum to simplify the objective function, establish the spares inventory decision model, and optimized by the marginal analysis and compile algorithm. The example proves that the model has good accuracy and practicality.
\end{abstract}

Keywords-Inventory decision, Repairable spares, Supply availability, Two indentures, Variance-to-mean ratio

\section{INTRODUCTION}

when predicting the stock of spares in the past, generally assume that the demand of the repairable spares follow the Poisson distribution, but actually purchasing next spare, not only demand is random, but the average may change, so not all spares are subject to the Poisson distribution; In addition, existing spares inventory decision models do not take into account the influence of the needs of multi-indenture to distribution of demand, which would generate more prediction errors.

Spares inventory decision requires forecasting average demand and some safety stock, therefore, to determine the distribution of demand means not only to use the mean of spares demand, but also to consider the variance-to-mean ratio, which has often been overlooked in the past decision research about the spares inventory. Most of spares demand in the short term follow the Poisson distribution with mean as a constant [1-3]; However, with the observation growing the difference average ratio has an increasing trend, the unique model in line with these observations is the incremental non-stable poisson process, then the Poisson distribution can be extended to the Negative binomial distribution with its variance over its mean, use negative binomial to establish the inventory decision model. In addition, when the multi-indenture demand of the spares takes place, even if the demand of the first indenture spares follows the Poisson distribution, but because the shortage of parts brings about some of its indirect for it, which causes the variance-to-mean ratio of the pipeline (product of average demand mean and average repair time) more than 1 , then the probability distribution meeting the needs of the first indenture spares is no longer the Poisson distribution, but the Negative binomial distribution, the prediction accuracy than the Poisson distribution. These are the two distributions of random demand, in fact, the demand process of some spares is not stochastic, but caused the loss of spares, such as turbine blades, landing gear, batteries, etc., which are subject to the Binomial distribution with its variance less than its mean[4].

Identifying demand distribution is only the first step of inventory decision, the second step is to determine the assessment indicators of inventory decision [5], and establish the inventory decision model to make the assessment on the supply system performance: it is necessary to evaluate the corresponding error of the itemized parts, but also assess the total integration error of all the various parts. The corresponding error standard of the itemized parts is its shortfall, but the total error standard is not a simple summation of shortfall. As the shortfall can be converted to the supply availability of aircraft, and supply availability index can predict the airport's aircraft availability next year, so it can be used as the evaluation index of spares inventory decision. From which the optimization objective of inventory decisions can be drawn: within the given total investment cost of spares, look for the highest supply availability[6-9], or limit the supply availability standard, for the minimal cost, these two goals is both based on seeking the minimal total shortfall, so their solutions are similar, the model establishes the inventory decision model only by the first target.

\section{ASSUMPTIONS}

(1) The number of the failures of all the aircraft parts is independent of each other.

(2) The requirements of the first indenture parts (Linereplaceable Unit, LRU) occurs in the base, if currently there are stocks then send out one, if not, once shortage of LRU happens. Both cases, no matter what kind, are at the base repairing faulty LRU, while in the repair process finds its own second indenture spares (Shop-replaceable Unit, SRU) is faulty, replace them if the SRU failure parts in stock to complete the repair, or once shortage of SRU occurs. Both 
cases, no matter what kind, are at the base repairing SRU. Each LRU failure only because of a fault in SRU, SRU repair will not be delayed for its parts are not in place. This paper mainly studys the two-indenture demand problems that the first indenture spares follow the Poisson distribution.

(3) Fault parts of a spares in the base can be repaired within a certain time, and are expressed by means of the probability distribution of $\mathrm{T}$, its demand meets the inventory balance equation $s=\mathrm{OH}+\mathrm{DI}-\mathrm{BO}[10]$, where, $\mathrm{s}$ is the necessary inventory amount, $\mathrm{OH}$ is the currently available inventory amount in the base, DI is the number of the repairing spares, $\mathrm{BO}$ is the spares shortage.

(4) No cannibalizations.

(5) In strict accordance with the principle "turn over the old and lead the new" to provide the spares for the outfield, no situation of LRU arrears.

\section{THREE-REQUIREMENT DISTRIBUTION OF SPARES}

\section{A. Negative binomial distribution}

When variance-to-mean ratio is greater than 1 , the demand of spares follows the Negative binomial distribution, namely

$$
\operatorname{Pr}(x)=\left(\begin{array}{l}
r+x-1 \\
x
\end{array}\right) p^{x}(x-p)^{r} \quad x=0,1,2, \ldots
$$

Where, $r>0,0<p<1$. Through the mean $\mu=\frac{r(1-p)}{p}$ and variance-to-mean ratio $V=\frac{1}{p}$ of the Negative binomial distribution, educe that

$$
r=\frac{\mu}{V-1}, p=\frac{1}{V}
$$

Thus, parameters $r$ and $p$ can be calculated by mean and observation, and generate a negative binomial probability distribution.

For the second-indenture demand, the method to estimate the parameters of its Negative binomial distribution is:

Suppose subscript $h$ as the index of LRU spares occuring two-indenture demand, the subscript $j$ is the index of its own SRU spares.

Because LRU, which occurs two-indenture damand, follows the Poisson distribution, so it's the demand of SRU also follows the Poisson distribution, namely

$$
m_{h}=\sum_{j=1}^{J} m_{h j}
$$

The actual demand of LRU follows the Negative binomial distribution, use the mean $E\left(X_{h}\right)$ and variance $\operatorname{Var}\left(X_{h}\right)$ of the pipeline to estimate the parameters $r$ and $p$ and the number of spares shortage $\operatorname{EBO}\left(s_{0} \mid E\left(X_{h}\right), \operatorname{Var}\left(X_{h}\right)\right)$, the mean and variance formulas of the pipeline are

$$
\begin{aligned}
& E\left(X_{i}\right)=m_{h} T_{h}+\sum_{j=1}^{J} \operatorname{EBO}\left(s_{h j} \mid m_{h j} T_{h j}\right) \\
& \operatorname{Var}\left(X_{h}\right)=m_{h} T_{h}+\sum_{j=1}^{J} \operatorname{VBO}\left(s_{h j} \mid m_{h j} T_{h j}\right)
\end{aligned}
$$

Where, $\operatorname{EBO}(s), \operatorname{VBO}(s)$ are the expectation, variance of the number of spares shortage, namely

$$
\begin{gathered}
\operatorname{EBO}(s)=\sum_{x=s+1}^{\infty}(x-s) \operatorname{Pr}\{\mathrm{DI}=x\} \\
\operatorname{VBO}(s)=E\left[B^{2}(X \mid s)\right]-[\operatorname{EBO}(s)]^{2} \\
=\sum_{x=s+1}^{\infty}(x-s)^{2} \operatorname{Pr}\{X=x\}-[\operatorname{EBO}(s)]^{2}
\end{gathered}
$$

\section{B. Poisson distribution}

When variance-to-mean ratio equal to 1 , the spares demand follows the Poisson distribution. According to Palm theorem [11], assume that the demand of any spares is subject to Poisson process with the average annual demand $m$, and each failed unit' repair time are independent, and obey the same distribution with the average repair time $T$, the steady-state probability distribution of number of repairing spares follows the Poisson distribution with mean $m T$, namely

$$
\operatorname{Pr}(x)=\frac{(m T)^{x} e^{-m T}}{x !} \quad x=0,1,2,3, \ldots
$$

\section{Binomial distribution}

When variance-to-mean ratio less than 1 , the spares demand follows the Binomial distribution, namely

$$
\operatorname{Pr}(x)=\left(\begin{array}{l}
n \\
x
\end{array}\right) p^{x}(1-p)^{n-x} \quad x=0,1,2, \ldots, n
$$

Where, $n>0,0<p<1$. Through the mean $\mu=n p$ and variance-to-mean ratio $V=1-p$ of the Binomial distribution, so

$n=\frac{\mu}{1-V}, p=1-V$

Thus, parameters $n$ and $p$ can be calculated by mean and observation, and generate a binomial probability distribution.

\section{INVENTORY DECISION MODEL AND SOLUTION}

\section{A. Inventory Decision Model}

Supply availability is the assessment indicators of spares inventory decision, it expresses the expectation value $A$ of percentage of number of the grounded aircrafts not due to any backorder, namely 
$A=100 \prod_{i=1}^{I}\left\{1-\frac{\mathrm{EBO}_{i}\left(s_{i}\right)}{N Z_{i}}\right\}^{Z_{i}}$

Where, $I$ is the number of items of spares, $Z_{i}$ is the number of spare $i$ installed in one plane, $N$ is the number of aircraft fleet, $s_{i}$ is the stock of spare $i$. Spares mentioned here, including LRU and SRU, so here the subscript $i$ is the indexes of all the spares.

On condition that there is no cannibalization, to search for the shortfall minimum is essentially equivalent to search for the supply availability maximum. Therefore, use the total shortfall minimum as the objective function, the total security funds as constraint condition to establish inventory decision optimization model, namely

$$
\left.\begin{array}{l}
\min z=\sum_{i=1}^{I} \mathrm{EBO}_{i}\left(s_{i}\right) \\
\sum_{i=1}^{I} c_{i} s_{i} \leq C
\end{array}\right\}
$$

Where, $c_{i}$ is the unit price of spare $i$ in the inventory, $C$ is total costs of the spares of the equipment system (integer value, its unit is ten thousand dollars).

\section{B. Model solution}

Model solution steps are: First, calculate variance-tomean ratio to determine what distribution the demand of spares follows, and calculate its parameters. Then, according to the inventory decision model, calculate the optimal inventory allocation, shortfall and supply availability of spares under the conditions of given stock funds and the total shortfall minimum.

The solution key is to solve the inventory decision model, it uses funds as resources, the total shortfall as the objective function, which is a typical problem of optimal allocation of resources; At the same time, the shortfall function is a convex function, meeting the requirements to search for the optimal allocation by the marginal analysis[12-14].

\section{EXAMPLE ANALYSIS}

There is 24 aircrafts in a base, it has three items of firstindenture spares LRU1, LRU2, LRU3, LRU2 has two items of second-indenture spares SRU1, SRU2, their probability causing LRU2 failure is 0.5 . The past ten years, from 2000 to 2009 , of demand statistical data of the five spares is shown in Table I.

Stocks of three LRU spares in late 2009 is respectively $(1,3,4)$, stocks of SRU1, SRU2 is 0 , no repairing spares, the budget of the five spares is 50 million dollars in the 2010, next, predict the stock configuration in 2010.

The shortage and costs of all the spares in different inventory configurations are shown in Table II.

Table. 2 shows, the total cost is 90 million dollars, five spares inventory configuration is $(10,13,7,15,15)$, the supply availability is equal to $92.7835 \%$.

Analysis:
(1) The shortage of the latter four spares are small, their backorder are unlikely to occur. The shortage of the first spare is 1.5302 , which is prone to occur. So, in the work of the next year, it is necessary to particularly look at the first spares of the security to prevent shortage. But, in fact, the shortage of spares is always inevitable, and spares support personnel can minimize the shortage of spares to make supply availability to maintain a reasonable level. In practice, the supply of spares includes normal and abnormal supply, normal supply is to provide the outfield with spares by base warehouse, which can be predicted by this model, abnormal supply is to supply through the emergency order, allocation, borrowing, etc, which is greater flexibility and is essential way to reduce the shortage of spares to further enhance the supply level of spares. As the supply availability of the normal supply is higher than $95 \sim 98 \%$, the stock capital would increase dramatically, so in order to maintain reasonable inventory level, meanwhile, to make the supply availability of spares to reach $95 \sim 98 \%$, generally set normal supply availability at 90 92\%, and the abnormal supply availability at between $5 \%$ to $6 \%$ [15]. In this example, if all spares are supplied by the base warehouse, to make the supply availability to reach $96.3133 \%$, there need to invest 65 million dollars, compared with 2010 budget increases $30 \%$. If combining with abnormal supply mode, you can achieve the same even higher supply level, but it can greatly reduce the budget so that more money concentrated in the spares supply command sector, spares is easier to raise.

(2) The method to verify the accuracy of the model prediction is: Calculate the actual supply availability of this year by the actual shortfall in 2010, and compare the supply availability of normal supply with the supply availability worked out by this model to determine if the model's prediction is accurate. When the base warehouse supplied outfield with the first spare in 2010, shortfalls occurred for twice, which is a normal supply, the supply availability at this time was $91.8403 \%$; However, the spares supply sector solved once of them through an emergency allocation of spares, so the actual shortfall is 1 , this time the supply availability reached $95.8767 \%$, the extra availability $4.0364 \%$ is accomplished by way of abnormal supply mode. Clearly, the relative error of the 2010' supply availability value forecasted by this model and actual value was only $0.9432 \%$, although slightly higher than normal formulated range $90 \sim 92 \%$, but still within the allowable range. Therefore, this model has good predictive accuracy.

(3) Excluding the two-indenture demand, the LRU2 follows the Poisson distribution, other conditions are constant, the supply availability at this time is $92.9066 \%$, compared with the actual value, the error is greater than the model' prediction. In addition, if five spares, regardless of their variance-to-mean ratio is greater than, equal to or less than 1 , are calculated by the Poisson distribution, supply availability may be up to $99.8959 \%$, which is much higher compared with the model predictions and actual values, deviation is very significant, this is caused by the Poisson distribution calculations even the variance not equal to 1 , so 
the key to get more accurate results is to predict according to the actually subject probability distribution.

\section{SUMMARIES}

(1) The Negative binomial distribution and Binomial distribution is the method to establish the demand forecasting model for the variance higher and lower than mean, but repairable spares not only obey the Poisson distribution with the variance equal to the mean, but also be subject to the two distribution, as to what distribution is adopted to predict can be decided by variance-to-mean ratio. If only adopt the Poisson distribution or not consider multiindenture demand, their prediction results are sometimes large different from the actual, compared to them, prediction of this model is more accurate.

(2) The model is the same with the inventory decision of all critical spares with a greater impact on system performance, as the system efficiency generated by these spares reflects the basic supply level, thus the results of their inventory decisions can be used as the fundamental basis of spares management decision next year. This is a systematic approach to optimize the overall inventory of spares and achieve the higher system efficiency.

\section{REFERENCES}

[1] HE Ya-qun; TAN Xue-feng; JIN Fu-lu. Demand Analysis of Aircraft Repairable Spares Based on Availability[J]. Systems Engineering and Electronics, 2004,26(6):848-849.

[2] CHEN Jian-hua. Research on Planning and Inventory Management of Repairable Spares Parts in Chinese Airlines[D]. Beijing: Beijing Jiaotong University, 2009.

[3] WANG Kun. Management of Aircraft Equipment Purchase and Stock[D]. Nanjing: Nanjing University of Aeronautics and Astronautics, 2002.

[4] DU Jun-gang; HE Ya-qun. On the Indexes for the Appraisal of Repairable Items Precise Support in the USAF[J]. Journal of Xuzhou Air Force College, 2007,18(4):87-90.
[5] LU Si-hai; ZHENG Jin-zhong; JI Ming. Aircraft Material Security Index Analysis Based on ARINC Model[J]. Warehouse management and technology, 2007(4):29-31.

[6] ZHANG Heng; HUA Xing-lai; XU Shao-mu. Inventory Decision Simulation Optimization Model of Repairable Spares System[J]. Systems engineering and electronics, 2009, 31(6):1510-1514.

[7] ZHANG Rui-chang; ZHAO Song-zheng. Consumptive Materials Spares to Determine the Order Model[J]. Military Operations Researc:h and Systems Engineering, 2004,18(4):40-42.

[8] FU Hong-yong; ZHAO Yu. The Analysis of Spare Cost and Operating Availability for Plane-group[J]. Aviation maintenance and engineering, 2004(3):52-53.

[9] LIU Yuan; CHEN Yun-xiang. Optimization Research on Aviation Spares Reserves Based on Availability and Cost Requirement[J]. Journal ofair force engineering university(natural science edition), 2009,10(6): 15-18.

[10] Craig C. Sherbrooke. Optimal Inventory Modeling of Systems: MultiEchelon Techniques, Second Edition[M]. He Bujie, Translate. Beijing: Publishing House of Electronics Industry, 2008.

[11] U Dinesh Kumar. Reliability, Maintenance and Logistic Support A Life Cycle Approach[M]. LIU Qinghua, SONG Ningzhe, Translate. BeiJing: Publishing House of Electronics Industry, 2010.

[12] FU Xing-fang; LI Ji-jun. A Stock Model and Its Algorithm for Restoring Air Materiel Beneath the Single-level Providing Condition $[\mathrm{J}]$. Operations Research and Management Science, 2003(12):92-95.

[13] FU Xing-fang; LI Ji-jun; LI Zong-zhi. A Stock Strategy Model for Restoring Air Materiel Based on the Two-level Providing Condition $[\mathrm{J}]$. Systems Engineering-Theory \& Practice, 2010,30(6):1138-1143.

[14] QU Hong-chun; JIANG Bo-song. Study on the Aeronautical Material System Reliability-based Optimization Model of Spares[J]. Aviation manufacturing technology, 2004(9):79-82.

[15] ZHAO Shu-fang. Study on Aircraft Spare Prognosticating Method based on RCM[D]. Nanjing: Nanjing University of Aeronautics and Astronautics, 2001.

TABLE I. STATISTICAL DATA OF ALL THE SPARES DEMAND

\begin{tabular}{|c|c|c|c|c|c|c|c|}
\hline \multicolumn{2}{|c|}{ Index of spares } & \multirow{2}{*}{$\boldsymbol{Z}_{\boldsymbol{i}}$} & $\boldsymbol{c}_{\boldsymbol{i}}$ & $\boldsymbol{T}$ & $\boldsymbol{m}$ & $\boldsymbol{V}$ & $\boldsymbol{m} \boldsymbol{T}$ \\
\cline { 1 - 6 }$i$ & $h / j$ & 2 & 6 & 0.5 & 10 & 1.5 & 5 \\
\hline 1 & $h=1$ & 1 & 1 & 0.45 & 16 & 1 & 7.2 \\
\hline 3 & $h=2$ & 1 & 2 & 0.2 & 5 & 0.8 & 1 \\
\hline 4 & $h=3$ & 1 & 0.1 & 0.7 & 8 & 1 & 5.6 \\
\hline 5 & $h=2 / j=1$ & 1 & 0.1 & 0.7 & 8 & 1 & 5.6 \\
\hline
\end{tabular}


TABLE II. SHORTAGE, THE SPARES IN DIFFERENT CONFIGURATIONS

\begin{tabular}{|c|c|c|c|c|c|c|}
\hline $\begin{array}{c}\text { LRU1 } \\
\left(s_{1}\right)\end{array}$ & $\begin{array}{c}\text { LRU2 } \\
\left(s_{2}\right)\end{array}$ & $\begin{array}{c}\text { LRU3 } \\
\left(s_{3}\right)\end{array}$ & $\begin{array}{c}\text { SRU1 } \\
\left(s_{4}\right)\end{array}$ & $\begin{array}{c}\text { SRU2 } \\
\left(s_{5}\right)\end{array}$ & $\begin{array}{c}\text { total shortage } \\
\text { (shortage of each base) }\end{array}$ & $\begin{array}{l}\text { total } \\
\text { costs }\end{array}$ \\
\hline$\ldots$ & $\ldots$ & $\ldots$ & $\ldots$ & $\ldots$ & $\ldots$ & $\ldots$ \\
\hline 6 & 11 & 6 & 11 & 11 & $\begin{array}{c}4.8645(4.2097,0.2126,0.4007,0.02 \\
07,0.0207)\end{array}$ & 61.2 \\
\hline 7 & 11 & 6 & 11 & 11 & $\begin{array}{c}4.0495(3.3947,0.2126,0.4007,0.02 \\
07,0.0207)\end{array}$ & 67.2 \\
\hline 7 & 11 & 6 & 12 & 11 & $\begin{array}{c}4.0370(3.3947,0.2126,0.4007,0.00 \\
82,0.0207)\end{array}$ & 67.3 \\
\hline 7 & 11 & 6 & 12 & 12 & $\begin{array}{c}4.0245(3.3947,0.2126,0.4007,0.00 \\
82,0.0082)\end{array}$ & 67.4 \\
\hline 8 & 11 & 6 & 12 & 12 & $\begin{array}{c}3.3000(2.6702,0.2126,0.4007,0.00 \\
82,0.0082)\end{array}$ & 73.4 \\
\hline 8 & 11 & 7 & 12 & 12 & $\begin{array}{c}3.0800(2.6702,0.2126,0.1808,0.00 \\
82,0.0082)\end{array}$ & 75.4 \\
\hline 9 & 11 & 7 & 12 & 12 & $\begin{array}{c}2.4572(2.0474,0.2126,0.1808,0.00 \\
82,0.0082)\end{array}$ & 81.4 \\
\hline 9 & 12 & 7 & 12 & 12 & $\begin{array}{c}2.3604(2.0474,0.1158,0.1808,0.00 \\
82,0.0082)\end{array}$ & 82.4 \\
\hline 10 & 12 & 7 & 12 & 12 & $\begin{array}{c}1.8431(1.5302,0.1158,0.1808,0.00 \\
82,0.0082)\end{array}$ & 88.4 \\
\hline 10 & 13 & 7 & 12 & 12 & $\begin{array}{c}1.7875(1.5302,0.0602,0.1808,0.00 \\
82,0.0082)\end{array}$ & 89.4 \\
\hline 10 & 13 & 7 & 13 & 12 & $\begin{array}{c}1.7824(1.5302,0.0602,0.1808,0.00 \\
31,0.0082)\end{array}$ & 89.5 \\
\hline 10 & 13 & 7 & 13 & 13 & $\begin{array}{c}1.7772(1.5302,0.0602,0.1808,0.00 \\
31,0.0031)\end{array}$ & 89.6 \\
\hline 10 & 13 & 7 & 14 & 13 & $\begin{array}{c}1.7752(1.5302,0.0602,0.1808,0.00 \\
11,0.0031)\end{array}$ & 89.7 \\
\hline 10 & 13 & 7 & 14 & 14 & $\begin{array}{c}1.7733(1.5302,0.0602,0.1808,0.00 \\
11,0.0011)\end{array}$ & 89.8 \\
\hline 10 & 13 & 7 & 15 & 14 & $\begin{array}{c}1.7725(1.5302,0.0602,0.1808,0.00 \\
04,0.0011)\end{array}$ & 89.9 \\
\hline 10 & 13 & 7 & 15 & 15 & $\begin{array}{c}1.7718(1.5302,0.0602,0.1808,0.00 \\
04,0.0004)\end{array}$ & 90 \\
\hline
\end{tabular}

